\title{
Designation and Investigate of a Full-Wave Controller Rectifier (FWCR) for Effect Source Inductance for Full Wave Rectifier
}

\author{
Kamarudin $\mathrm{Kh}^{\mathrm{a}}$, Ramli M. S., A. W. SitiSufiah, Razali N. F. and S. A. Nordin \\ Faculty of Electrical Engineering, Universiti Teknologi MARA, 81750 Masai, Johor, Malaysia
}

\begin{abstract}
The full wave rectifier with RL load consists of all the SCRs as controlled devices. This full wave converter can operate in quadrants and output voltage can be negative in case of inductive loads. The power factor is poorer than a half converter, as the full bridge converter is primarily used to control the DC motor speed [1].The purpose of this paper is to solve higher ripper power supply in a full wave controlled rectifier using an RL load of $240 \mathrm{rms}$ voltage, $50 \mathrm{~Hz}$ with an attached source inductance, $\mathrm{Ls}$ of $10 \mathrm{mH}$ value. The average output voltage can be varied from 100-200VDC. The performance of a full wave rectifier with source inductance is to create conduction of four thyristor simultaneously with overlapping angle. The result obtained is with an efficiency of $50.18 \%$ at output RL Load.
\end{abstract}

\section{Introduction}

Power electronic is one of the important branches of electronic and electrical engineering. It deals with conversion and control of electrical energy. A power electronic system performs conversion of electrical energy. It also controls the amount of electrical energy to be given to the output. Power electronics combines power, electronics and control. Control deals with the steadystate and dynamic characteristics of a closed-loop system. Power deals with the static and rotating power equipment for generation, transmission and distribution of electric energy. Based on that, impedance source in power electronics provides an efficient power converter to a load with a wide range of electrical power conversion applications (dc-dc,dc-ac,ac-ac,ac-dc) [1]. The impedance-source network is broadly classified into two categories based on magnetics; 1) non-transformer based; and 2) coupled or transformer. Each topology has distinct features and advantages [2]. The single-phase full converter, the period of $\alpha$ to $\pi$, the input voltage Vs and the input current are positive which results in power flow from the power supply to the load. With this condition, the converter is in rectification mode. In the period $\pi$ to $\pi+\alpha$, the input voltage is negative and the input current is positive which reverses power flow from the load to the supply. Hence, the converter is in inverse mode [3].

\section{FWCR without source inductance (Ls)}

Figure 1 shows a Full-Wave Rectifier without Source Inductance. This figure is basic on a full wave rectifier by

\footnotetext{
a Corresponding author: khairul@johor.uitm.edu.my
}

controlling four SCRs with a firing angle controller. To obtain the output voltage of the circuit, derivations must be following as in equation (1).

$$
\mathrm{Vdc}=\frac{2}{2 \pi} \int_{\alpha}^{\pi+\alpha} \operatorname{Vm} \sin w t d(w t)=\frac{2 \mathrm{~m}}{\pi} \cos \alpha
$$
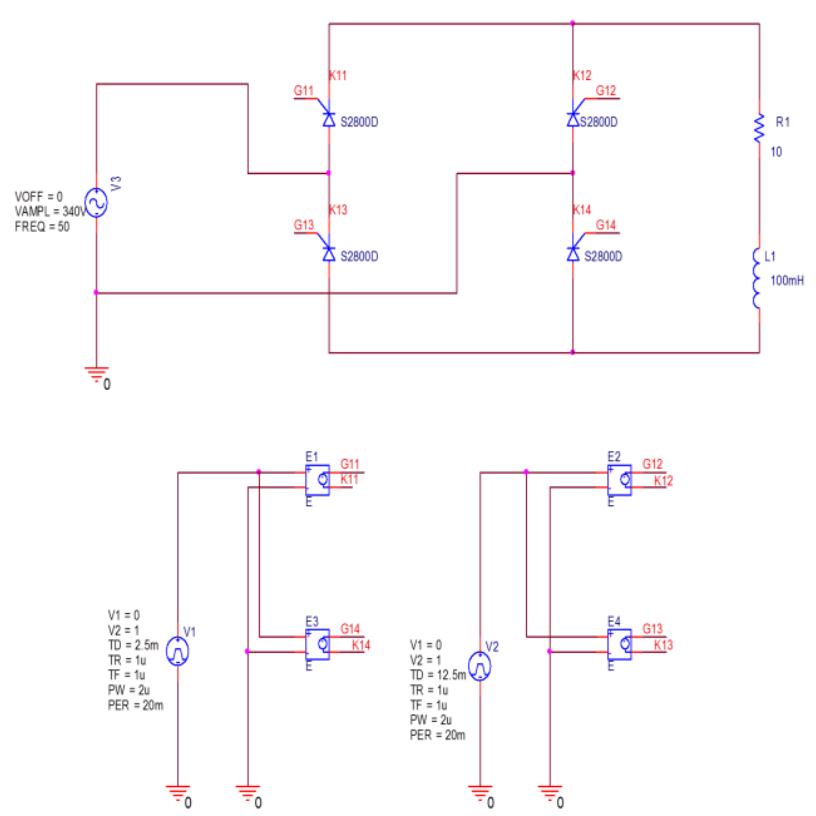

Figure 1. Full-Wave rectifier without source inductance.

The values of the firing angle must be calculated by a given target of an output voltage which is 160 Volts. The calculations involved are stated below:

$$
\operatorname{Vodc}=\frac{2(340)}{\pi} \cos \alpha
$$




$$
\operatorname{Cos} \alpha=\frac{160}{216.45}=0.7391
$$$$
\alpha=42.34^{\circ}
$$$$
T=\frac{1}{\mathrm{f}}=\frac{1}{50}=20 \mathrm{~ms}
$$

$$
42.34^{\circ} \rightarrow \frac{42.34^{\circ} \times 20 m s}{360^{\circ}}=2.35 \mathrm{~ms}
$$

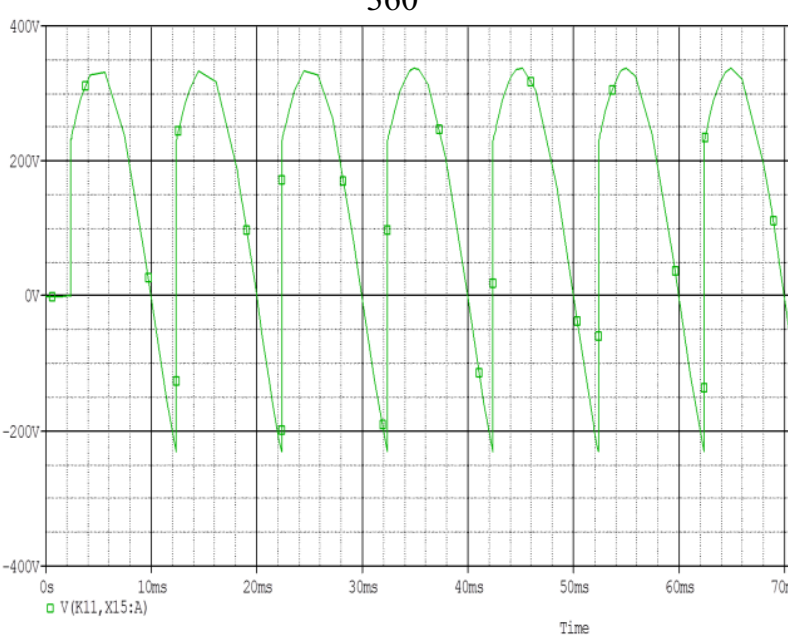

Figure 2. The output voltage without source inductance.

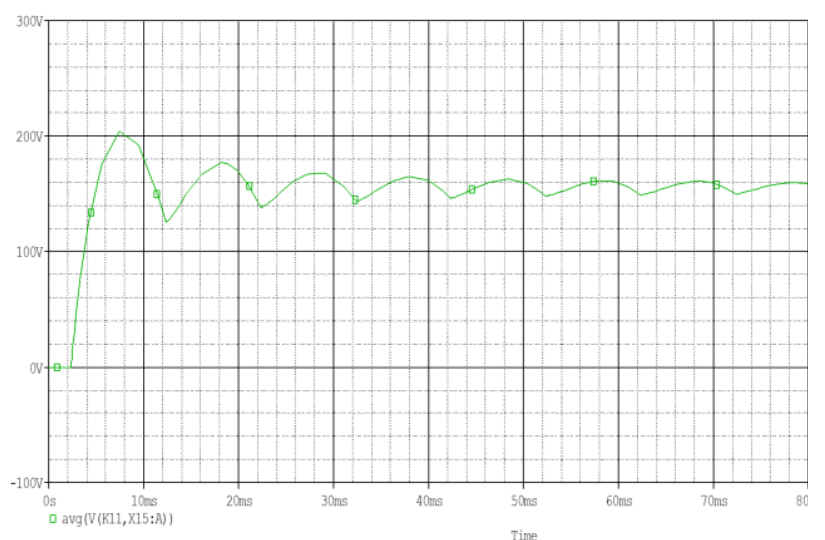

Figure 3. The average output voltage without source inductance.

By referring Figure 3, the value obtained from the simulation is 157.7 Volts. The measurement value is near the calculated value which is 160 Volts. Calculations done after this will have an average output of 160 Volts as a reference target when adding source inductance in section 3 .

\section{FWCR with the source inductance (Ls) is $10 \mathrm{mH}$}

Based on Figure 5, the simulation for $\alpha$ is $12.53 \mathrm{~ms}$ and $\beta$ is $12.905 \mathrm{~ms}$. These values can be calculated to find the values of an angle shifting source with the values of a total $360^{\circ}$ cycle. Based on the calculation shown, the value of degrees in $\beta$ is $52.31^{\circ}$. The function of $\beta$ is to determine the effect of source impedance to the value of the average output voltage and rms output voltage. Figure 4 shows a Full-Wave Rectifier with Source Inductance.
To analyze the output voltage of the circuit, derivations are following as in equation (2).

$$
\operatorname{Vodc}=\frac{\mathrm{Vm}}{\pi} \int_{\beta}^{\pi+\alpha} V m \operatorname{Sin} \mathrm{wtd}(\mathrm{wt})
$$
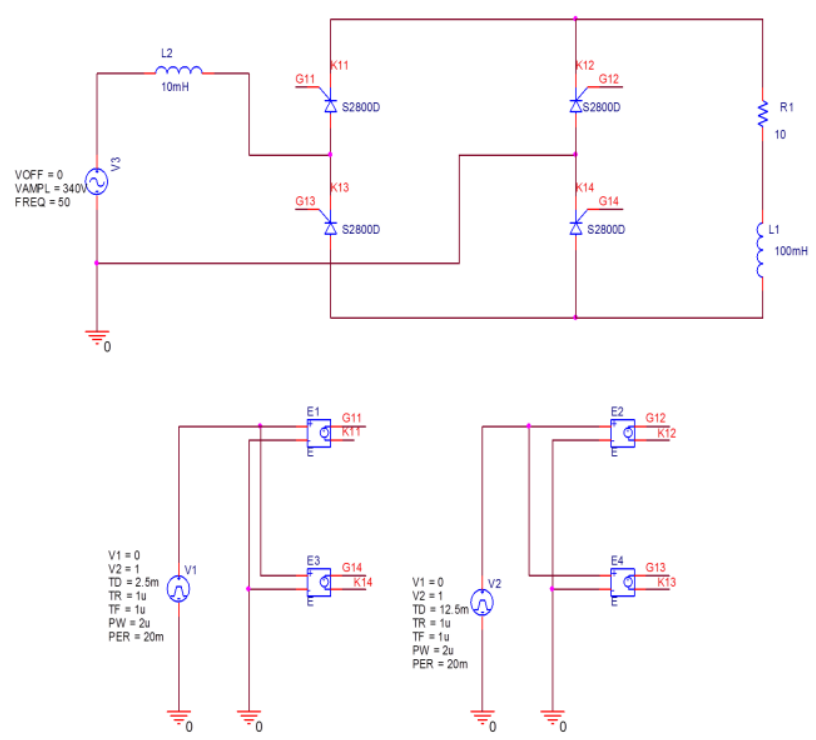

Figure 4. Circuit full rectifier with source inductance.

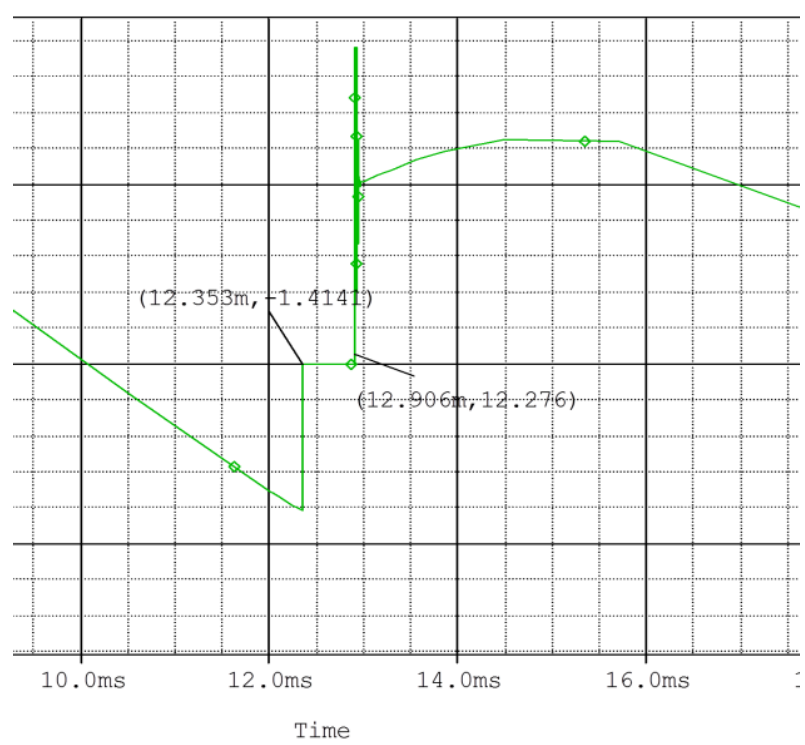

Figure 5. The values of $\beta$.

The value of average voltage which involves the shifting of $\beta$ is 146.16 Volt. This value is less from the average output voltage from the result of not using the source impedance. By using equation (3), we get 13.84Volts.

$$
\text { Vlosses }=\int_{\alpha}^{\beta} \text { Vm sin wt d }(w t)
$$

The result of calculation of average current and rms output current have different result, this happen because due to the effect of using with inductance at load. This results in voltage losses from the $\alpha$ to $\beta$ period by the effect of an impendence source. The equation (4) is used for rms voltage output. The final calculation is 233.11 Volts. 


$$
\operatorname{Vorms}^{2}=\frac{1}{\pi} \int_{\beta}^{\pi+\alpha} V m^{2} \operatorname{Sin}^{2} w t \mathrm{~d}(\mathrm{wt})
$$

$$
\begin{aligned}
\text { Iodc } & =\frac{1}{\pi} \int_{\beta}^{\pi+\alpha}\left[10.312 \sin (w t-1.2626)+20.64 e^{-0.3183 w t}\right] d(w t) \\
& =\frac{10.312}{\pi}\left[\begin{array}{l}
-0.3033 \cos w t-0.9529 \sin w t \\
-6.2897 e^{-0.3138 w t}
\end{array}\right]_{0.913}^{\pi+0.739} \\
& \text { Iodc }=15.363 \mathrm{~A}
\end{aligned}
$$

The calculation of rms output current is 19.12 Ampere. From the calculation of output current, the performance of efficiency can reach up to $50.14 \%$.

$$
\begin{aligned}
\text { Iorms }^{2} & =\frac{10.312^{2}}{\pi} \int_{\beta}^{\pi+\alpha}\left[\begin{array}{l}
\sin ^{2(}(w t-1.2626) \\
+2.002^{2} e^{-0.1013 w t}
\end{array}\right] d(w t) \\
& =\frac{53.17}{\pi} \int_{\beta}^{\pi+\alpha}\left[\begin{array}{l}
1-\cos (2 w t-2.5252) \\
+8.016 e^{-0.1013 w t}
\end{array}\right] d(w t)
\end{aligned}
$$

Iorms $=19.21 \mathrm{~A}$

Performance of rectifier with source inductance

$$
\begin{aligned}
\eta \% & =\frac{\text { VodcIodc }}{\text { VormsIorms }} \\
& =\frac{(146.16)(15.363)}{(233.11)(19.21)} \\
& =0.5014
\end{aligned}
$$$$
\eta \%=50.14 \%
$$
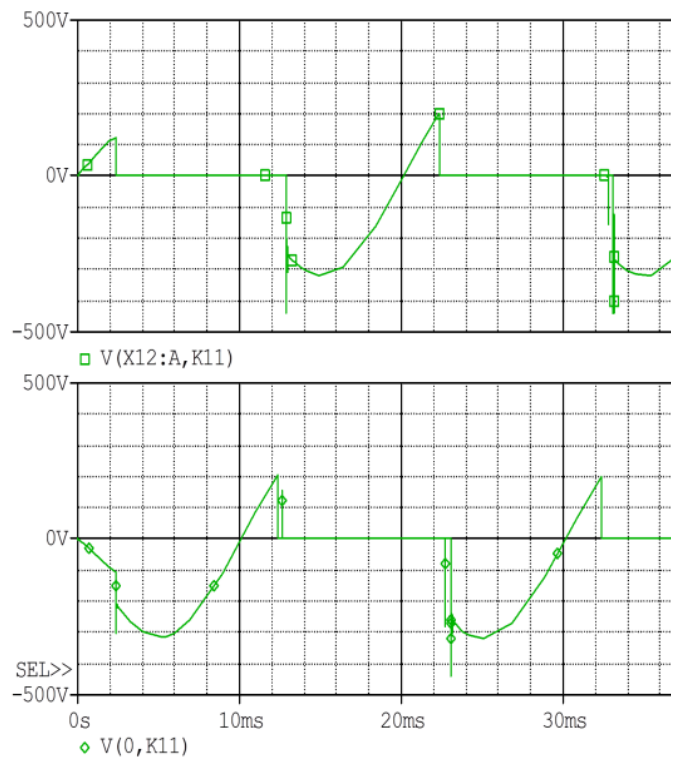

Figure 6. The voltage anode to cathode on thyristor.

Based on the simulation result, the thyristor is turned on by applying a positive voltage between its gate and cathode as in Figure 6. Once a thyristor is turned on by a gating signal and its anode current is greater than the holding current, the device continues to conduct due to positive feedback even if the gating signal is removed.

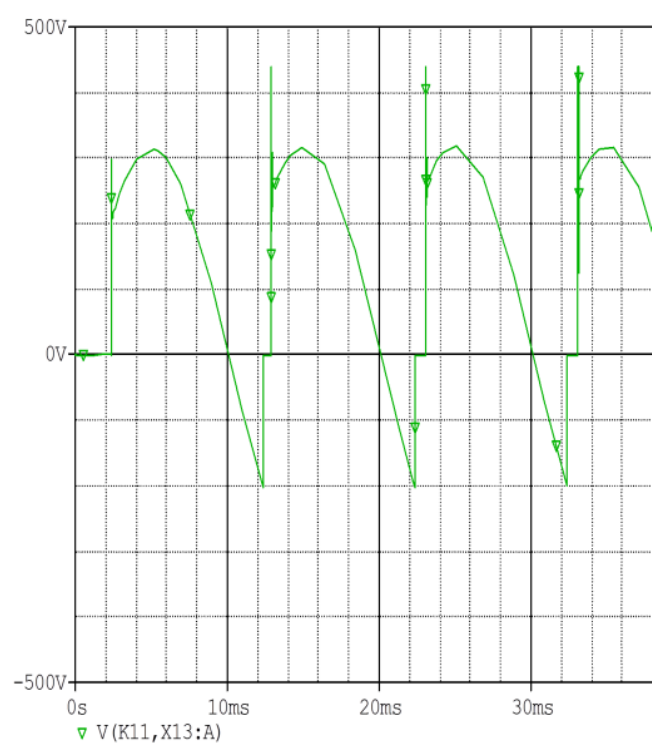

Figure 7. The output voltage.

Figure 7 and Figure 8 show the simulation has dropped $\mathrm{V}_{\text {odc }}$ as in the previous calculation. The simulation gives a value of 140.6 Volts. This value is the nearest to the previous calculation.

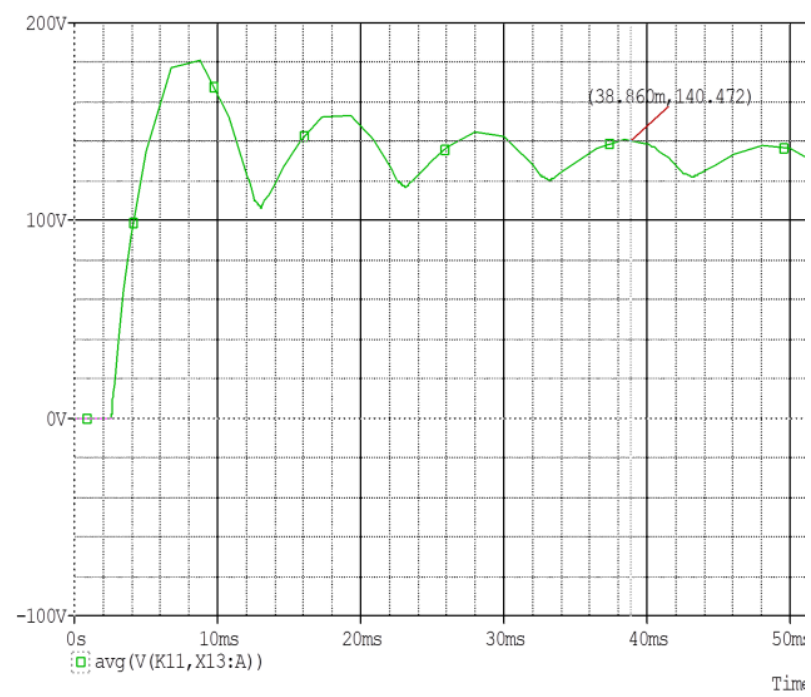

Figure 8. The average output voltage.

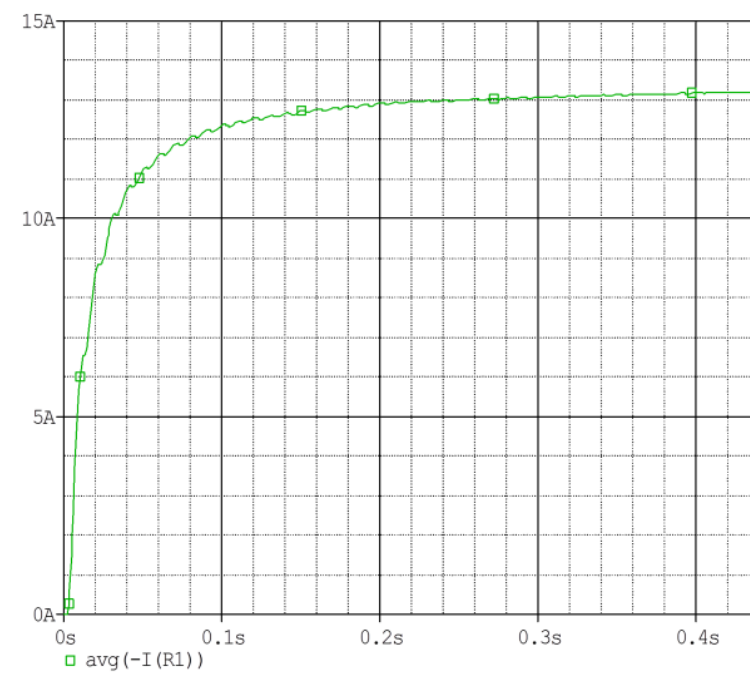

Figure 9. The average output current. 


\section{Conclusion}

Based on the assumption of inductance is infinite, normally the converters are fed from the supply transformer. The inductance of the supply transformer becomes an input to the converter. This inductance is called source inductance, and it affects the performance of the converter. Common source inductance is the loop inductance shared by the gate driver and the main power transfer path [4]. Potential application of the full-wave rectifier circuit is implanted in medical instruments, inductive power transfer to weapons, power transfer using space reflectors and power generation in space [5]. The impedance source is also suitable in the implementation of the capital cost of a small wind turbine driven in a electrical power generation system, which is very competitive compared to that of other known nonpolluting and renewable energy source [6].

When the load inductance is infinite, it is acceptable to assume that the load current is continuous and steady without ripple. Let the firing angle be ' $a$ ' and the commutation overlap period last from $w t=a$ till $w t=b$. During the period, $\alpha<\mathrm{wt}<\beta$, the output voltage is zero because all the SCRs are in conduction. If the SCRs are ideal, the drop across an SCR in conduction is zero and hence the output voltage is zero. During $\beta<\mathrm{wt}<(\pi+\alpha)$, the output voltage equals $\mathrm{V}_{\mathrm{m}}{ }^{*} \operatorname{Sin}(\mathrm{wt})$ and then the average output voltage can be obtained like in Figure 16.The period from $\alpha$ to $\beta$ is call overlap period. The angle $\beta$ is called overlap angle. This overlap angle is to create simultaneous conduction between SCR 1 \& SCR 2 and SCR3 \&SCR4.

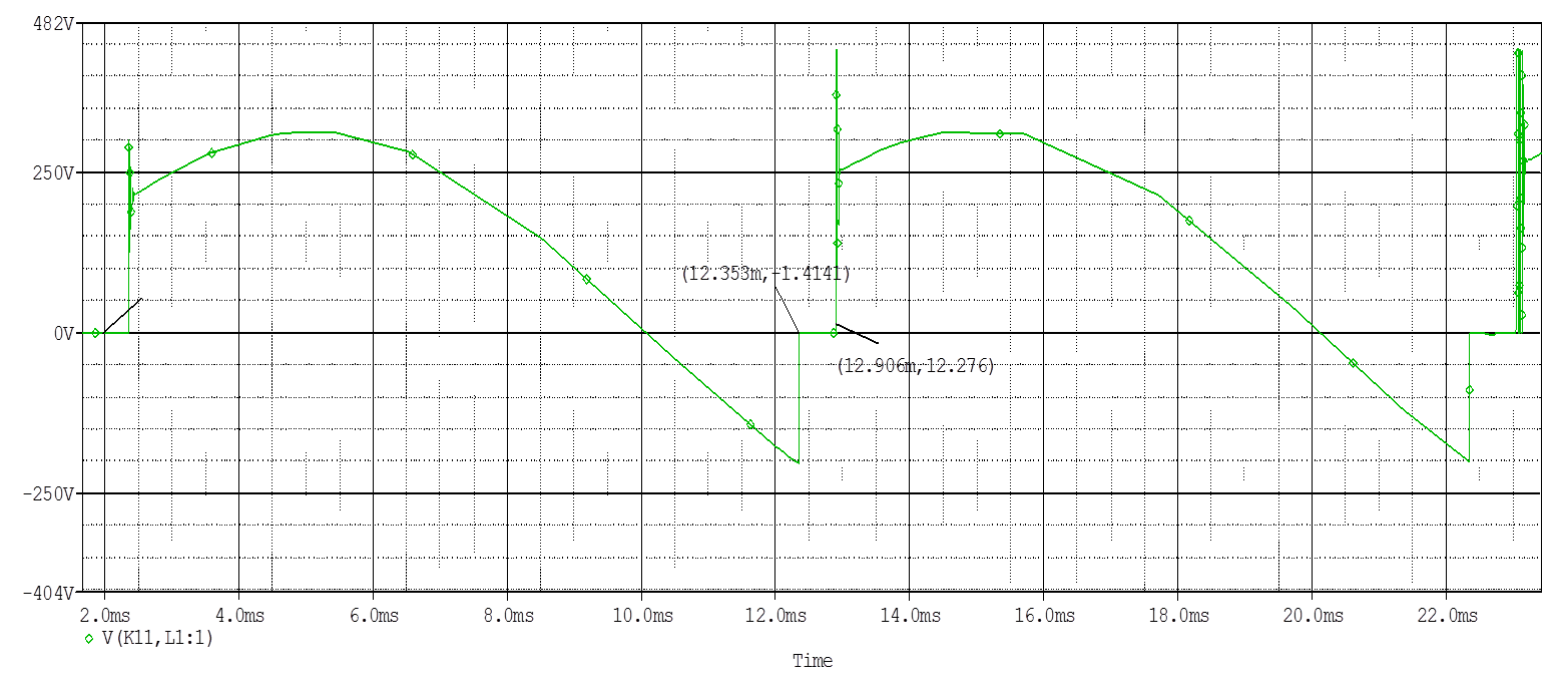

Figure 10. The output voltage analysis.

\section{References}

1. F. Z. Peng, "Z-source inverter," in Proc. Ind Appl. Conf, 2, pp 775-781 (Oct 13-18, 2002)

2. Yam P. Siwakoti, Fang Zheng Peng, Frede Blaabjerg, Poh Chiang Loh and Graham E. Town, "ImpedanceSource Networks for Electric Power Conversion Part I: A Topologies Review," IEE Transation Power Electronc, 30, 2 (2015)

3. Muhammad H.Rashid, "PowerElectronic :circuit device and applications, $2^{\text {nd }}$ edition," Prentice-Hall international, Inc., (1993), pp. 434-435
4. Bo Yang, Jason Zhang, "Effectandutilization of common source inductance in synchronous rectification," International rectifier (2005), IEEE, pp 1407-1400.

5. Richard J. Arthur, "Maximum Power Transfer for Full Wave rectifier circuit", member IEEE Noval surface weapons center, pp. 454-461

6. R. Bharanikumar, R. Senthikumar, and Nirmal Kumar, "Impedance Source for Wind Turbine Driven Permananet Magnet Generator," Power System Technology and IEEE Power India Conference Powercon, (2008) 